Article

\title{
Comparison of Water Pretreatment Devices for the Measurement of Polar Odorous Compounds
}

\author{
Joo-Yeon Lee ${ }^{1}$, Trieu-Vuong Dinh ${ }^{1}$, Dong-June Kim ${ }^{1}{ }^{\mathbb{D}}$, In-Young Choi ${ }^{1}$, Ji-Won Ahn ${ }^{2}$, \\ Shin-Young Park ${ }^{2}$, Yoo-Jin Jung ${ }^{1}$ and Jo-Chun Kim ${ }^{1, *}$ \\ 1 Department of Civil and Environmental Engineering, Konkuk University, 120 Neungdong-ro, Gwangjin-Gu, \\ Seoul 05029, Korea; joooyeon07@gmail.com (J.-Y.L.); dinhtrieuvuong@gmail.com (T.-V.D.); \\ fullhousek9@naver.com (D.-J.K.); force@konkuk.ac.kr (I.-Y.C.); 1dud123@naver.com (Y.-J.J.) \\ 2 International Climate and Environmental Research Center, Konkuk University, 120 Neungdong-ro, \\ Gwangjin-Gu, Seoul 05029, Korea; jwahn81@konkuk.ac.kr (J.-W.A.); cnung2@gmail.com (S.-Y.P.) \\ * Correspondence: jckim@konkuk.ac.kr; Tel.: +82-2-450-4009; Fax: +82-2-3437-8654
}

Received: 27 August 2019; Accepted: 23 September 2019; Published: 27 September 2019

\begin{abstract}
A major problem of measuring polar compounds in the air is water vapor. Therefore, it is important to use a water pretreatment device prior to sampling and analysis. However, many studies have reported the occurrence of many problems following the application of an existing water pretreatment device. Accordingly, the performance of a Desolvator-K that was developed by the authors and two commercial coolers were investigated and compared in this study. Water vapor removal efficiency, recovery rate, and reproducibility of polar odorous compounds (i.e., methyl ethyl ketone (MEK), isobutyl alcohol (i-BuAl), methyl isobutyl ketone (MIBK), butyl acetate (BuAc), styrene) in air were taken into account. It was found that the Desolvator- $K$, the Cooler- $G$, and the Cooler-K showed $91.6 \%, 67.2 \%$, and $62.1 \%$ water vapor removal efficiency, respectively, at the relative humidity of $90 \%$. In terms of recovery rate, after water vapor removal devices, the Desolvator-K, the Cooler-G, and the Cooler-K revealed average recoveries of $96.6-103 \%, 81-101 \%$, and $88.6-100 \%$, respectively. Reproducibility of odorous compounds under all conditions of the Desolvator-K, the Cooler-G, and the Cooler-K were $5.94 \%, 31.2 \%$, and $8.14 \%$ of relative standard deviation (RSD), respectively. Therefore, it is suggested that the Desolvator-K should be established as a water pretreatment device for the MEK, i-BuAl, MIBK, and BuAc compounds in the air.
\end{abstract}

Keywords: water pretreatment device; desolvator; KPASS-Odor; cooler; odorous compounds; water soluble compounds; polar compounds

\section{Introduction}

A water pretreatment device is an apparatus that can remove only water vapor presented in sample gas in order to improve accurate and reliable sampling and analysis. Interference and loss of analytes occur when samples containing water vapor are taken from the atmosphere [1]. Furthermore, the measuring instruments could be damaged by the remaining water vapor. Water vapor taken with a sample gas could disturb the adsorption capacity of adsorbents, destabilize the baseline of the chromatograph, cause column damage, and change the retention times of sample compounds [2]. It might also clog the transfer line of the instrument or reduce the sensitivity of the measurement process [3]. In terms of detectors, the filament condition could be changed during the operation of a mass spectrometer (MS), which results in response variation [4].

In order to minimize problems caused by water vapors, the U.S. EPA and the Korean Ministry of Environment recommend the use of a water pretreatment device at the fore of the sampling 
system or analyzer. Nafion ${ }^{\circledR}$ dryers and coolers were especially recommended according to sampling environment [5-9].

Nafion ${ }^{\circledR}$ dryers are the most common water pretreatment devices. Thus, they have been widely applied to the analytical process of corrosive gases due to their high chemical durability [7]. The Nafion ${ }^{\circledR}$ dryer could remove water vapors by water adsorption/desorption through the Nafion ${ }^{\circledR}$ membrane [10]. On the other hand, a cooler adopting a Peltier could remove water vapors by reducing the temperature of sampled gases to dew point. Hence, water vapor in air is condensed into its liquid phase when it passes through the temperature-lowered impinger and removed. The water vapor removal of the cooler depends on the surface area and length of an impinger, gas-flow rate, and the material and temperature of the cooling part [11].

Although Nafion ${ }^{\circledR}$ dryers have been widely employed as water pretreatment devices, some polar compounds, such as alcohols, aldehydes, ketones, and water soluble esters were found to be removed [12-14]. Gong et al. [15] found that the heat regeneration of a Nafion ${ }^{\circledR}$ dryer depletes and rearranges some hydrocarbons in the sample. In addition, Son et al. [16] reported that artifact formation could occur for benzene in a Nafion ${ }^{\circledR}$ dryer. The U.S. EPA [17] suggested that when the volatile organic compound (VOC) was analyzed using a Nafion ${ }^{\circledR}$ dryer as a water pretreatment device, polar compounds were removed with water vapor, and they could not be identified. Seo et al. [18] reported that a Nafion ${ }^{\circledR}$ dryer should not be applied for the measurement of low molecular VOCs because contamination might occur in the dryer. In addition, a water pretreatment device should be carefully selected, so that there is no loss of polar VOCs and no introduction of contaminants, because the polar VOC could be lost by a water pretreatment device, including a Nafion ${ }^{\circledR}$ dryer [4].

Likewise, many studies $[4,12-18]$ stated that the most commonly used Nafion ${ }^{\circledR}$ dryer in the world was inadequate as a water pretreatment device for some compounds. It is very important to select a suitable water pretreatment device by the characteristics of the compound for accurate analysis and to protect the analytical instrument. In addition, because the amount of the analyte is usually very small, the degree of analyte loss by the water pretreatment device is very important.

In order to solve this issue, a Desolvator-K called KPASS (Key compound PASSer)-Odor that could selectively remove water vapors in a different manner was investigated in this study. The manufactured Desolvator-K applied in this study is a water pretreatment device that inherited the principle of the Desolvator used by Son et al. [19], and it is an upgraded version of the Desolvator. The Desolvator-K in this study employed the Mpemba effect which was not depicted in the previous study [19] by removing water vapor with a temperature difference using Peltier. The Mpemba effect is a phenomenon in which hot water is frozen faster than cold water in certain conditions [20,21]. Water vapor contained in the sample passed through the tube and transformed to frost on the inner wall of the tube. It was found that the water vapor removal and recovery of Desolvator-K depended on the length and material of an inside tube and temperature of Peltier.

In this study, we evaluated the performance of the manufactured Desolvator-K as a water pretreatment device. The Desolvator-K was also compared with coolers that are widely used in the world and remove water vapor using Peltier. In order to evaluate the performance of water pretreatment devices, the water vapor removal and the recovery of odorous compounds were investigated. Odorous compounds used in this study were polar odorous compounds present in indoor and ambient air, which are difficult to analyze due to their high solubility in water.

\section{Materials and Methods}

\subsection{Materials}

Ketones (methyl ethyl ketone (MEK), methyl isobutyl ketone (MIBK)), alcohols (isobutyl alcohol (i-BuAl)), and acetates (butyl acetate (BuAc)) in VOCs have high solubility values in water. They are regulated and administered as odorous compounds in the Republic of Korea. The physical properties of the target compounds are shown in Table 1. MEK, i-BuAl, MIBK, and BuAc showed high solubility 
values, whereas styrene was used as a comparative compound because its solubility in water is low (Table 1) [22].

Table 1. Target odorous compounds.

\begin{tabular}{|c|c|c|c|c|c|}
\hline \multicolumn{2}{|c|}{ Compound } & \multirow{2}{*}{ CAS No. } & \multirow{2}{*}{$\begin{array}{l}\text { Molecular Weight } \\
\qquad(\mathrm{g} / \mathrm{mol})\end{array}$} & \multirow{2}{*}{$\begin{array}{l}\text { Solubility * } \\
\text { (g/L) }\end{array}$} & \multirow{2}{*}{$\begin{array}{l}\text { Vapor Pressure } \\
\left(\mathrm{mmHg}, 20^{\circ} \mathrm{C}\right)\end{array}$} \\
\hline Full Name & Short Name & & & & \\
\hline Methyl ethyl ketone & MEK & $78-93-3$ & 72.11 & 275 & 78 \\
\hline Isobutyl alcohol & $\mathrm{i}-\mathrm{BuAl}$ & $78-83-1$ & 74.12 & 95 & 9 \\
\hline Methyl isobutyl ketone & MIBK & $108-10-1$ & 100.16 & 19.1 & 16 \\
\hline Butyl acetate & $\mathrm{BuAc}$ & $123-86-4$ & 116.16 & 6.8 & 9 \\
\hline Styrene & $\mathrm{S}$ & $100-42-5$ & 104.15 & 3 & 5 \\
\hline
\end{tabular}

\subsection{Water Pretreatement Device}

The water pretreatment device was installed at the prior part of the sampling system to remove water vapor for more accurate analysis. A KPASS-Odor (NAD-P100, Nara Control Inc., Republic of Korea), a Cooler-G (TC-Standard 6122, Buhler technologies, Germany), and a Cooler-K (Electric cooler SEC-2001B, Saehan Hi-Tech, Ltd., Republic of Korea) were used as the water pretreatment devices.

\subsection{Analytical System}

The sampling and analytical method of the target compounds was based on ISO 16000-6, ISO 16017-1, ISO 16017-2, and ES 09307.a [23-26].

A gas chromatography (GC) (6890, Agilent Technologies, USA) equipped with a thermal desorber (TD) (Unity 2, Markes international, UK) and mass spectrometer (MS) (5975, Agilent Technologies, USA) were used to analyze target compounds. The analytical column was capillary column DB-624 $(60 \mathrm{~m} \times 0.320 \mathrm{~mm} \times 1.80 \mu \mathrm{m})$, and a cold trap filled with Tenax TA (U-T9TNX-2S, Markes international, UK). The adsorption tube filled with Tenax TA in a stainless-steel tube (C1-AXXX-5003, Markes International, UK) was used to capture the sample gases. The adsorption tubes were used after the thermal-wash stabilization step according to the test method [26,27]. Operating conditions of the measurement instruments are summarized in Table 2.

\subsection{Experiment Procedure}

\subsubsection{Analytical Methods}

In order to evaluate the reliability of the analytical instrument, a calibration curve was created and its linearity was confirmed. To verify the reliability of the measured data, the method detection limit (MDL) was used. Furthermore, the limit of quantification (LOQ) and precision were evaluated. In this study, a mixed standard gas (5 Odor Mix, Rigas Co., Ltd., Republic of Korea), including 10.3 ppm of MEK and 10.4 ppm of i-BuAl, MIBK, BuAc, and styrene, was used.

The validity of the calibration curve was verified at $10-100 \mathrm{ppb}$, which was the valid concentration range according to the test method. Five concentrations (i.e., 10, 20, 40, 80, $100 \mathrm{ppb}$ ) were selected in the quantitative range. Samples were prepared in Tedlar bags (SKC, USA) with $10 \mathrm{~L}$ of volume. Mixed standard gas (5 Odor Mix, Rigas Co., Ltd., Republic of Korea) was injected into each of the 5 Tedlar bags (10, 20, 40, 80, and $100 \mathrm{~mL}$ ) and filled with $\mathrm{N}_{2}$ (99.999\%, Rigas Co., Ltd., Republic of Korea) to prepare a sample for the calibration curve. Then, the prepared samples were introduced to adsorption tubes for $5 \mathrm{~min}$ at a flow rate of $100 \mathrm{~mL} / \mathrm{min}$ using a suction pump equipped with a flow meter.

To verify the reliability of the measured data, a sample with a $0.5 \mathrm{ppb}$ of concentration was prepared for detectable concentration by using a gastight gas syringe (SGE, Australia). It was introduced into 
the adsorption tubes for $5 \mathrm{~min}$ at a flow rate of $100 \mathrm{~mL} / \mathrm{min}$, the sample analysis was repeated 7 times. Detection limits were calculated by multiplying the standard deviation obtained from these analyzed results with 3.14. The LOQ was calculated by multiplying the standard deviation with 10 .

Table 2. Operating parameters of thermal desorber (TD) and gas chromatography (GC)/mass spectrometer (MS).

\begin{tabular}{|c|c|c|c|c|}
\hline \multicolumn{5}{|c|}{ TD (Unity 2, Markes International, UK) } \\
\hline \multirow{2}{*}{ Predesorption } & \multirow{2}{*}{\multicolumn{2}{|c|}{$\begin{array}{l}\text { Prepurge time } \\
\text { Split }\end{array}$}} & 1 & $(\min )$ \\
\hline & & & 0 & $(\mathrm{~mL} / \mathrm{min})$ \\
\hline \multirow{3}{*}{ Sample tube Desorption } & \multicolumn{2}{|c|}{ Tube hold } & 10 & $(\min )$ \\
\hline & \multicolumn{2}{|c|}{ Oven temperature } & 300 & $\left({ }^{\circ} \mathrm{C}\right)$ \\
\hline & \multicolumn{2}{|c|}{ Split } & 0 & $(\mathrm{~mL} / \mathrm{min})$ \\
\hline \multirow{5}{*}{ Cold trap Desorption } & \multicolumn{2}{|c|}{ Per-trap fire purge/min } & 1 & $\left({ }^{\circ} \mathrm{C}\right)$ \\
\hline & \multicolumn{2}{|c|}{ Trap low } & -10 & $\left({ }^{\circ} \mathrm{C}\right)$ \\
\hline & \multicolumn{2}{|c|}{ Trap high } & 300 & $\left({ }^{\circ} \mathrm{C}\right)$ \\
\hline & \multicolumn{2}{|c|}{ Trap hold } & 5 & $(\min )$ \\
\hline & \multicolumn{2}{|c|}{ Split } & 0 & $(\mathrm{~mL} / \mathrm{min})$ \\
\hline \multirow{2}{*}{\multicolumn{5}{|c|}{$\begin{array}{l}\text { GC (6890, Agilent Technologies, USA) } \\
\text { MS (5975, Agilent Technologies, USA) }\end{array}$}} \\
\hline & & & & \\
\hline & $\begin{array}{c}\text { Rate } \\
\left({ }^{\circ} \mathrm{C} / \mathrm{min}\right)\end{array}$ & $\begin{array}{c}\text { Temp } \\
\left({ }^{\circ} \mathrm{C}\right)\end{array}$ & $\begin{array}{l}\text { Hold } \\
(\min )\end{array}$ & $\begin{array}{l}\text { Run Time } \\
\text { (min) }\end{array}$ \\
\hline Initial & - & 40 & 5 & 5 \\
\hline Ramp 1 & 10 & 240 & 5 & 30 \\
\hline
\end{tabular}

In addition, the precision was determined using $80 \mathrm{ppb}$ of standard gases. The standard gas, which had the concentration within the calibration-curve range, was injected 3 times to evaluate the standard deviation (SD). Then, $80 \mathrm{~mL}$ of mixed standard gas (5 Odor Mix, Rigas Co., Ltd., Republic of Korea) was injected into the $10 \mathrm{~L}$ Tedlar bag and filled with $\mathrm{N}_{2}$ (99.999\%, Rigas Co., Ltd., Republic of Korea) using a mass flow controller (Line Tech, Republic of Korea) calibrated with a soap bubble meter to prepare a sample for precision evaluation.

\subsubsection{Water Vapor Removal}

To verify the water vapor removal performance of the water pretreatment device, humid gas was prepared using a lab-manufactured humidity generator at $2 \mathrm{~L} / \mathrm{min}$ of flow rate. Its relative humidity (RH) was $50 \%$ and $90 \%$. The flow rate of the humid gas passing through the water pretreatment device was maintained at $100 \mathrm{~mL} / \mathrm{min}$. Humid gas generated from the humidity generator was installed to directly connect to the water pretreatment device. Humidity was measured by a humidity sensor (Testo 645, Testo, Germany) at the inlet and outlet of the water pretreatment device. All experiments were carried out under the same condition $\left(25 \pm 1^{\circ} \mathrm{C}, 1 \mathrm{~atm}\right)$. The coolers and Desolvator- $\mathrm{K}$, which were using Peltier, were set to an optimal temperature according to their characteristics. Data were collected by using the data-save mode of the humidity sensor with a $10 \mathrm{~s}$ interval for $20 \mathrm{~min}$. The experiment was repeated 3 times.

\subsubsection{Odorous Compound Recovery by Water Pretreatment Device}

To identify the effect of the water pretreatment device on target compound analysis, various concentrations of the target gases were introduced into the water pretreatment devices to investigate their recoveries.

A sample of each concentration was prepared by diluting a humid gas and mixed standard gas (5 Odor Mix, Rigas Co., Ltd., Republic of Korea) in a 10 L Tedlar bag (see Table 3). Then, 20 and $100 \mathrm{~mL}$ of 
mixed standard gas (5 Odor Mix, Rigas Co., Ltd., Republic of Korea) were injected into each Tedlar bag, and the sample was filled with humid gas of each relative humidity. In the odorous compound recovery experiment, a Tedlar bag was used to mix the humid gas with the target compounds. Therefore, maximum relative humidity was selected at $80 \%$ to prevent water condensation inside the Tedlar bag.

Table 3. Dilution method for recovery experiment by water pretreatment devices.

\begin{tabular}{|c|c|c|c|c|}
\hline \multicolumn{2}{|l|}{ Concentration } & \multicolumn{2}{|c|}{ Volume } & \multirow{2}{*}{$\begin{array}{c}\text { Working Gas } \\
\text { Concentration }(\mathrm{ppb})\end{array}$} \\
\hline $\begin{array}{l}\text { Primary Standard Gas } \\
(\mathrm{ppm})\end{array}$ & RH (\%) & Humid Air (mL) & $\begin{array}{l}\text { Primary Standard Gas } \\
\qquad(\mathrm{mL})\end{array}$ & \\
\hline \multirow[t]{2}{*}{$10 *$} & \multirow[t]{2}{*}{50} & 9980 & 20 & $\begin{array}{c}20 \text { range } \\
(20.6-20.8)\end{array}$ \\
\hline & & 9900 & 100 & $\begin{array}{l}100 \text { range } \\
(103-104)\end{array}$ \\
\hline \multirow[t]{2}{*}{$10 *$} & \multirow[t]{2}{*}{80} & 9980 & 20 & $\begin{array}{l}20 \text { range } \\
(20.6-20.8)\end{array}$ \\
\hline & & 9900 & 100 & $\begin{array}{l}100 \text { range } \\
(103-104)\end{array}$ \\
\hline
\end{tabular}

Note: * $10.3 \mathrm{ppm}$ for MEK and $10.4 \mathrm{ppm}$ for i-BuAl, MIBK, BuAc and styrene. Working gas concentration will be presented in this study as $20 \mathrm{ppb}$ or $10 \mathrm{ppb}$ instead of a concentration range.

In order to confirm the initial concentration, the sample was adsorbed to the adsorption tube at a flow rate of $100 \mathrm{~mL} / \mathrm{min}$ for $5 \mathrm{~min}$ using a suction pump equipped with a flow meter, as shown in Figure 1a. To investigate the effect of the water pretreatment device on the target compounds, the adsorption tube was connected to the end of the water pretreatment device, and the sample was adsorbed at a flow rate of $100 \mathrm{~mL} / \mathrm{min}$ for $5 \mathrm{~min}$ after water vapor was removed, as shown in Figure $1 \mathrm{~b}$.

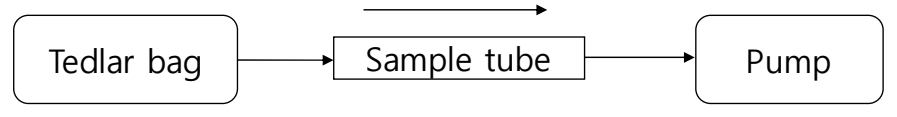

(a)

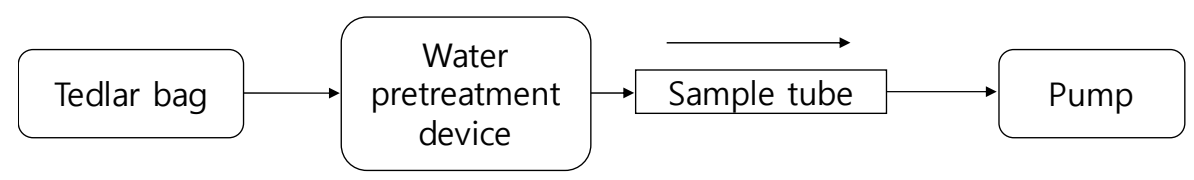

(b)

Figure 1. Sampling train for the comparison of the target chemical recovery rate: (a) Without water pretreatment device; (b) with water pretreatment device.

\section{Results and Discussion}

\subsection{Quality Assurance}

To evaluate the reliability of the detector, a calibration curve was prepared by diluting the mixed standard gas (5 Odor mix, Rigas Co., Ltd., Republic of Korea) with 10, 20, 40, 80, and 100 ppb. The determination coefficients for MEK, MIBK, i-BuAl, BuAc, and styrene were 0.9999, 0.9997, 0.9998, 0.9993 , and 0.999 , respectively. Thus, they were reliable values because they were all above 0.98 , as suggested in the test method. In order to verify the reliability of the measured data, the MDL was calculated by repeatedly analyzing the sample for seven times at a concentration of $0.5 \mathrm{ppb}$. The MDL values of MEK, MIBK, i-BuAl, BuAc, and styrene were $0.17,0.12,0.39,0.09$, and $0.06 \mathrm{ppb}$, respectively. In the test method, MDL target values were less than $1 \mathrm{ppb}$ of styrene, and the other compounds were less than $10 \mathrm{ppb}$. The calculated MDL values were found to be acceptable with respect to concentration 
ranges in this study. In addition, the LOQ was $0.55,0.381 .23,0.30$, and $0.20 \mathrm{ppb}$ for MEK, MIBK, $\mathrm{i}-\mathrm{BuAl}, \mathrm{BuAc}$, and styrene, respectively. In terms of precision, $80 \mathrm{ppb}$ concentration was selected for a precision test and analyzed three times and evaluated as standard deviation (SD). The calculated SD of MEK, MIBK, i-BuAl, BuAc, and styrene was 1.82\%, 5.03\%, 2.55, 4.76\%, and 9.84\%, respectively. Precision presented in the test method was less than $10 \%$ SD.

\subsection{Water Vapor Removal}

Water vapor removal experiments were conducted to compare water vapor removal performance, which is the basic characteristic of water pretreatment devices. Experiments were conducted with a relative humidity of $50 \%$ and $90 \%$.

Water vapor removal efficiency of each water pretreatment device is presented in Figure 2. As shown in Figure 2, all water pretreatment devices of concern revealed higher water vapor removal efficiency at $90 \% \mathrm{RH}$ than those at $50 \% \mathrm{RH}$. The Desolvator-K, which revealed the highest water vapor removal efficiency, was able to reduce $50 \%$ and $90 \% \mathrm{RH}$ to less than $10 \%$. Son et al. [19] reported that the water vapor removal of a Desolvator was $94.6-96.1 \%$ when water vapor removal was compared by varying water vapor content and flow rate, and it was not much influenced by water vapor content or flow rate.

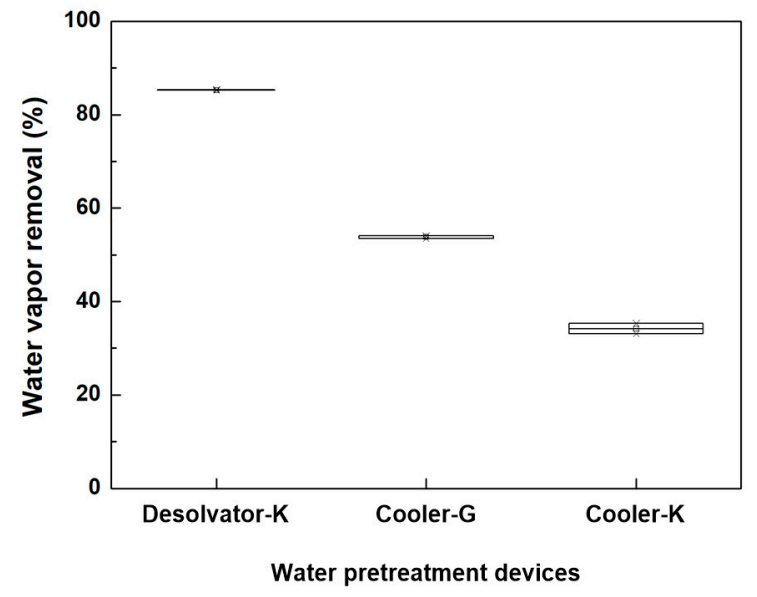

(a)

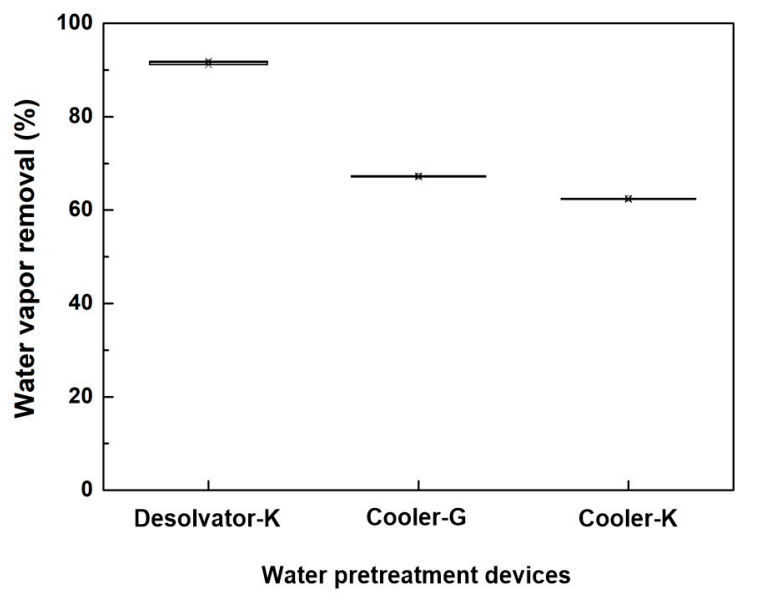

(b)

Figure 2. Water vapor removal of water pretreatment devices; (a) 50\% RH; (b) 90\% RH.

The Cooler-G and the Cooler-K denoted a different water vapor removal, due to the internal shape of their impingers. The impinger of the Cooler-G was confirmed to have a large inner contact area with a spiral shape. On the other hand, since the inner shape of the impinge belonging to Cooler-K was flat, its surface area that could come in contact with the humid gas was smaller than that of the Cooler-G.

\subsection{Odorous Compound Recovery of Water Pretreatment Device}

\subsubsection{Recovery of Odorous Compounds}

In order to investigate the effect of water pretreatment devices on odorous compound analysis, experiments were conducted to compare the recovery of odorous compounds with respect to different devices. The recovery rates of the odorous compounds are illustrated in Figure 3.

When water vapor was removed by Desolvator-K, the average recovery rates of MEK, i-BuAl, MIBK, BuAc and styrene were 103\%, 96.6\%, 99.5\%, 97.9\%, and 99.2\%, respectively. For the Cooler-G, the average recovery rates of MEK, i-BuAl, MIBK, BuAc and styrene were 101\%, 81\%, 96.3\%, 94.6\%, and $90.9 \%$, respectively. Likewise, average recovery rates of MEK, i-BuAl, MIBK, BuAc and styrene were $100 \%, 91.7 \%, 94.4 \%, 90.8 \%$, and $88.6 \%$, respectively, when the experiment was conducted with the Cooler-K. 


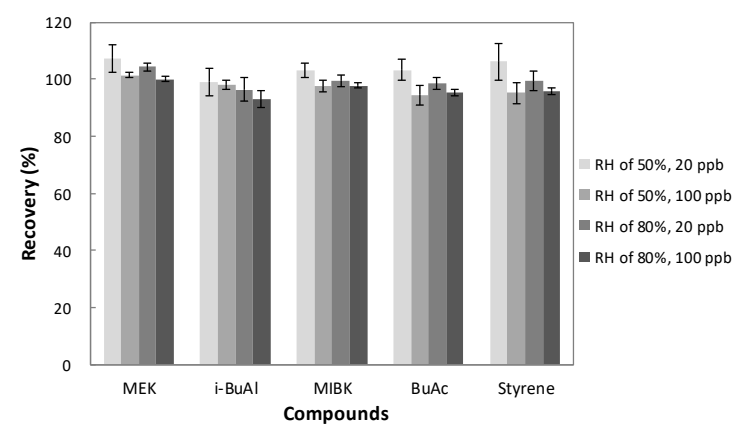

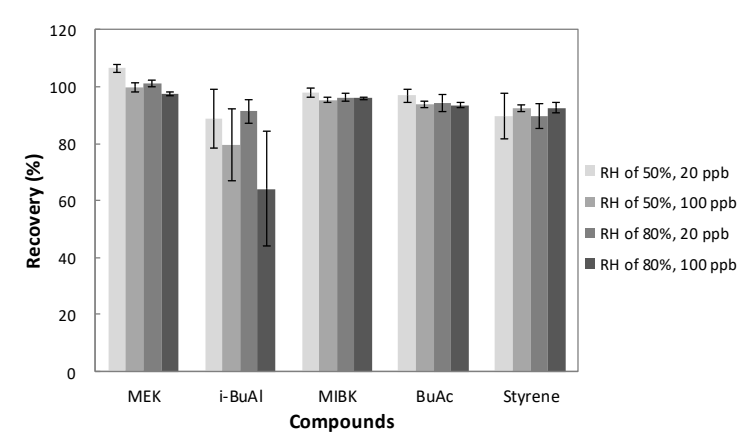

(b)

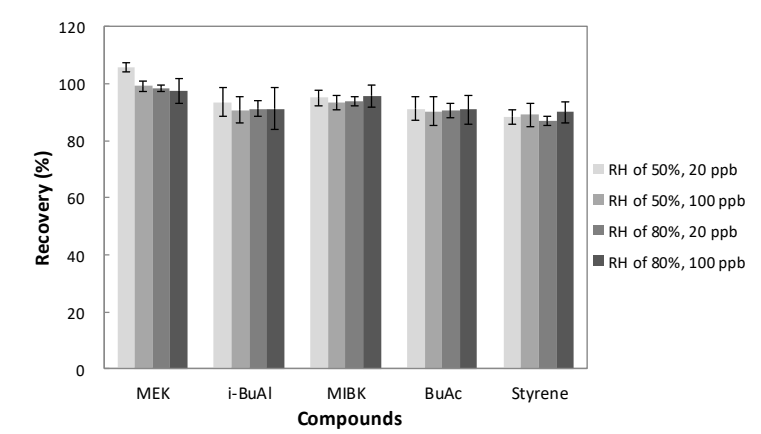

(c)

Figure 3. Recovery of each water pretreatment device: (a) Desolvator-K; (b) Cooler-G; (c) Cooler-K.

The Desolvator-K revealed the highest recovery rates of all target compounds in all conditions even though MEK, i-BuAl, MIBK and BuAc have high solubility in water. This pattern was similar to a previous study. Son et al. [19] reported that recovery rates of sulfur compounds that also have high solubility in water were $\geq 97 \%$ for when the Desolvator was used to remove water vapor.

In terms of $\mathrm{i}-\mathrm{BuAl}$, its recovery rate was lower than that of other compounds when the coolers were used. In contrast, although MEK has the highest solubility in water, its recovery rate was higher than that of i-BuAl. MEK dissolved rapidly in condensed water in the cooler, but it had a high vapor pressure (see Table 1), so it would be rapidly vaporized to maintain material equilibrium. However, i-BuAl dissolved quickly in the condensed water, but the time to equilibrium was delayed due to its low vapor pressure (see Table 1), and it would take time to revaporize. Thus, the i-BuAl recovery rate was low when the coolers were used.

The recovery of the Cooler-G was higher than that of the Cooler- $K$ for all compounds except $\mathrm{i}-\mathrm{BuAl}$ due to the different impinger material between the Cooler-G and the Cooler-K. The impinger material of the Cooler-G was Teflon, and that of the Cooler-K was glass. Deming et al. [28] investigated the absorption of gaseous compounds using various tube materials. It was reported that Teflon was not influenced by humidity or gas concentration compared to glass. Therefore, the Cooler-G with a Teflon impinger seemed to have higher recovery than the Cooler-K with a glass impinger.

The U.S. EPA [4] reported that certain polar VOCs (amines, ketones, alcohols, and some ethers) were lost when water vapor was removed by a Nafion ${ }^{\circledR}$ dryer. Hence, the recovery of total non-methane organic compounds was reduced by 20-30\%. Moreover, Zielinska et al. [12] reported that all polar compounds were lost when a Nafion ${ }^{\circledR}$ dryer was used to remove water vapor. Some paraffins, olefins, and aromatic compounds were declined, and the total non-methane hydrocarbon concentration was reduced by $10-20 \%$. In addition, Dunder et al. [29] noted that a large number of air pollutants are water soluble. Thus, a condensation dryer such as a cooler could remove analytes due to the interaction of condensed water and gas. Kim [30] found that when water vapor was removed by using a cooler, $\mathrm{O}_{3}$, which is a highly reactive compound, and $\mathrm{SO}_{2}$, which is a water soluble compound, showed recoveries of $61.1-88.0 \%$ and $38.6-80.7 \%$, respectively. According to these studies, when the Nafion ${ }^{\circledR}$ dryer and the cooler were used as water pretreatment devices for the analysis of polar materials, it was judged 
that the analytical accuracy would be decreased. This suggests that the Desolvator-K should be an alternative way to remove water vapor for the analysis of polar compounds.

\subsubsection{Reproducibility}

The analytical reproducibility of recovery rates for odorous compounds was also measured to investigate the performance of water pretreatment devices. The reproducibility of the compounds was evaluated as the relative standard deviation (RSD) of triplicated experiments. Experimental results are demonstrated in Figure 4. A high RSD value indicates that the concentration of the odorous compound recovered after water vapor removal was not consistent.

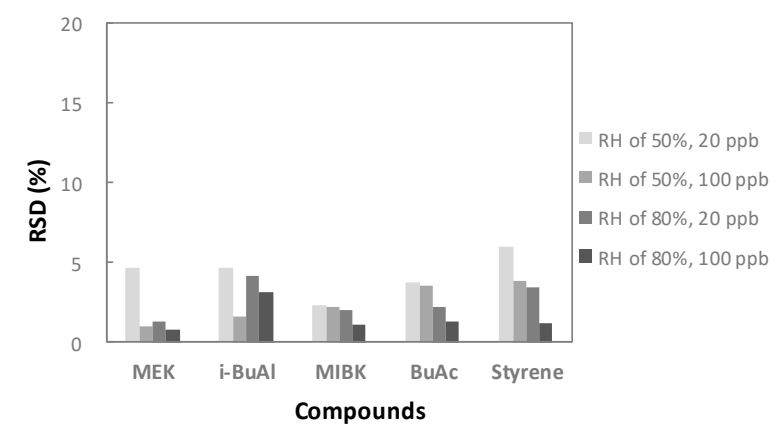

(a)

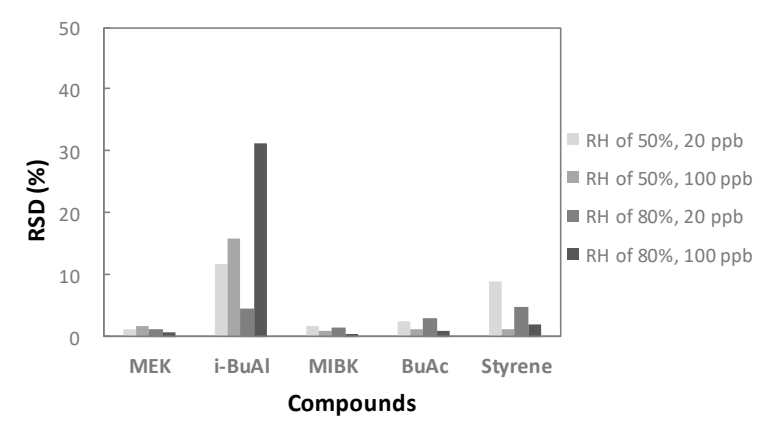

(b)

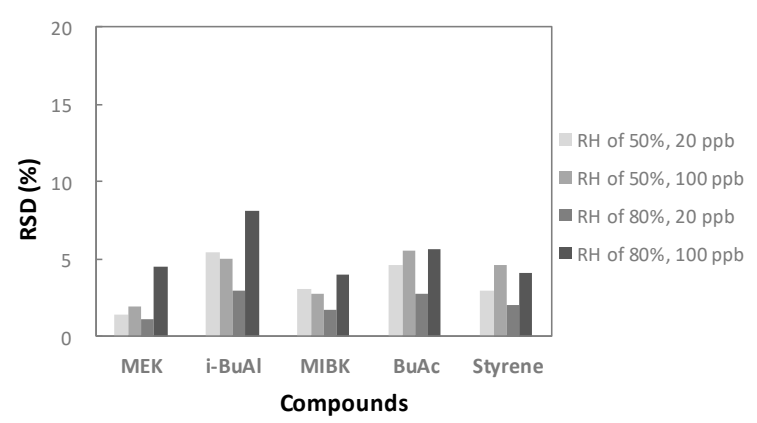

(c)

Figure 4. Reproducibility of odorous compounds after removing water vapor: (a) Desolvator-K; (b) Cooler-G; (c) Cooler-K.

As shown in Figure 4, the Desolvator-K denoted stable reproducibility because RSD was $\leq 5.95 \%$ for all compounds under all conditions. The Cooler-G showed consistent reproducibility for MEK, MIBK, and BuAc (i.e., RSD $\leq 3.08 \%$ ), but very unstable reproducibility for i-BuAl (i.e., RSD = 4.44-31.2\%). This pattern was similar to that of the Cooler-K. The Cooler-K showed stable reproducibility of less than $5.66 \%$ RSD for all compounds except i-BuAl, but the RSD for i-BuAl indicated the fluctuation reproducibility (i.e., $\mathrm{RSD}=2.92-8.14 \%$ ). These phenomena occurred due to the inner shape of the Cooler-G's impinger and the characteristics of i-BuAl, as mentioned in Sections 3.2 and 3.3.1.

The Desolvator-K consists of a short and straight tube with which water vapor is removed. In contrast, the cooler has an impinger in which a vortex occurs due to flow direction from downward to upward. Therefore, the cooler showed high RSD values because the gas flow was not uniform.

In the present test method, it was recommended to use the Nafion ${ }^{\circledR}$ dryer as a water pretreatment device for the target compounds concerned in this study [6,8]. Therefore, Im et al. [31] analyzed the removal of the MEK, i-BuAl, MIBK, and BuAc compounds when using a Nafion ${ }^{\circledR}$ dryer as a water pretreatment device. It was reported that recoveries of the four compounds were less than $20 \%$ when the Nafion ${ }^{\circledR}$ dryer was installed. For more accurate and reliable analysis, the water pretreatment device should be able to selectively remove water vapor that affects sample analysis without influencing analytes. However, the Nafion ${ }^{\circledR}$ dryer was not appropriate as a water pretreatment device for the 
MEK, i-BuAl, MIBK and BuAc compounds. Consequently, it was very important to select a suitable water pretreatment device according to the target analyte.

\section{Conclusions}

A comparison between a Desolvator-K and two commercial coolers as water pretreatment devices was carried out in this study. The target compounds were MEK, i-BuAl, MIBK, and BuAc, which were the polar odorous compounds of VOCs in air, and styrene was used as a simple comparison compound. The water vapor removal efficiency, recovery rate, and reproducibility were evaluated for each device.

Water vapor removal was confirmed as the basic performance of the water pretreatment device. The manufactured Desolvator-K, which showed the highest water vapor removal (85.3-91.6\%), could reduce sample $\mathrm{RH}$ to less than $10 \%$ after removing the water vapor. However, the samples of Cooler-G $(53.9-67.2 \%)$ and Cooler-K (34.2-62.1\%) were found to be around 30\% RH. Therefore, it was observed that the Desolvator- $\mathrm{K}$ is more suitable as a water pretreatment device than the coolers because they could be damaging to the instrument or disturb analyte detection if unremoved water vapor is introduced to the analyzer.

In the recovery test of the odorous compounds, the manufactured Desolvator-K showed the highest recovery rates (96.6-103\%) and reproducibility (less than 5.94\% RSD) for each target compound under all conditions. The Cooler-G, on the other hand, showed recovery rates of $81-101 \%$ and unstable reproducibility of less than $31.2 \%$ for all target compounds under all conditions. The Cooler-K showed recovery rates of $88.6-100 \%$ for all target compounds under all conditions and somewhat unstable reproducibility of less than $8.14 \%$. Thus, the coolers showed unstable recovery rates and reproducibility depending on the compound. It was also considered that it was not appropriate to use an unreliable water pretreatment device when analyzing a trace amount of a compound and requiring low humidity because a cooler has a relatively low water vapor removal. On the other hand, the Desolvator-K also denoted higher water vapor removal and higher recovery than the coolers. Therefore, it could be considered that the Desolvator-K can be used as a water pretreatment device for the odorous compounds used in this study.

Therefore, Desolvator-K has higher water vapor removal efficiency and higher analyte recovery rate than other coolers. In terms of durability, both water pretreatment devices have a similar durability (about 3-5 years). Instead, the Desolvator-K might have a higher initial cost than other devices, and might consume more energy depending on the use environment. Nonetheless, a suitable water pretreatment device is pivotal key for accurate and reliable measurements for the characteristics of each analyte. Particularly, when polar and water soluble compounds with trace amounts are measured, the selection of a water pretreatment device capable of selectively removing water vapor without any interference on the analyte is the most important issue. As a result of this study, the Desolvator-K could be used as a water pretreatment device for the MEK, i-BuAl, MIBK, BuAc, and styrene compounds. The comparison with coolers was only conducted in this study. However, the Nafion ${ }^{\circledR}$ dryer is widely used all over the world. Consequently, a comparison between the Desolvator-K and the Nafion ${ }^{\circledR}$ dryer should be implemented in future work.

Author Contributions: Conceptualization, J.-Y.L. and J.-C.K.; methodology, J.-Y.L., T.-V.D., and J.-C.K.; validation, J.-Y.L.; formal analysis, J.-Y.L., T.-V.D., D.-J.K., J.-W.A., and S.-Y.P.; investigation, J.-Y.L. and D.-J.K.; resources, J.-Y.L. and Y.-J.J.; data curation, J.-Y.L. and I.-Y.C.; writing—original-draft preparation, J.-Y.L. and T.-V.D.; writing一review and editing, J.-Y.L., T.-V.D., and J.-C.K.; visualization, J.-Y.L.; supervision, J.-C.K. and T.-V.D.; project administration, J.-Y.L. and J.-C.K.

Funding: This research was supported by the R\&D Center for Green Patrol Technologies through the R\&D for Global Top Environmental Technologies (Grant number 1485016147) funded by Ministry of Environment(MOE), Republic of Korea.

Acknowledgments: This research was supported by the R \& D Center for Green Patrol Technologies through R\&D for Global Top Environmental Technologies funded by Ministry of Environment (MOE), Republic of Korea.

Conflicts of Interest: The authors declare no conflict of interest. 


\section{References}

1. Kistenev, Y.V.; Kuryak, A.N.; Makogon, M.M.; Ponomarev, Y.N. The system for dehumidification of samples in laser gas analysis. Atmos. Ocean. Opt. 2012, 25, 92-95. [CrossRef]

2. Haberhauer-Troyer, C.; Rosenberg, E.; Grasserbauer, M. Investigation of membrane dryers and evaluation of a new ozone scrubbing material for the sampling of organosulphur compounds in air. J. Chromatogr. A 1999, 852, 589-595. [CrossRef]

3. Sundin, N.G.; Tyson, J.F.; Hanna, C.P.; McIntosh, S.A. The use of nafion dryer tubes for moisture removal in flow injection chemical vapor generation atomic absorption spectrometry. Spectrochim. Acta Part B At. Spectrosc. 1995, 50, 369-375. [CrossRef]

4. U.S. EPA. Technical Assistance Document for Sampling and Analysis of Ozone Precursors; U.S. EPA: Research Triangle Park, NC, USA, 1998.

5. The Korea Ministry of Environment; The Korea National Institute of Environmental Research. Air Pollution Monitoring Network Installation and Operation Guidelines; The Korea Ministry of Environment: Sejong, Korea, 2018; Available online: http://www.me.go.kr/home/web/public_info/read.do;jsessionid= ZoQ68eydUH63yakjSV1mZ90hrC6nKwmuIaIGNXrdIwh87RtigvMG7pOtmCAYSzFJ.meweb1vhost_ servlet_engine1?pagerOffset=0\&maxPageItems $=10 \&$ maxIndexPages $=10 \&$ searchKey $=\&$ searchValue $=$ \&menuId=10357\&orgCd=\&condition.publicInfoMasterId=2\&condition.deleteYn=N\&publicInfoId=426\& menuId=10357 (accessed on 7 November 2018).

6. The Korea Ministry of Environment. VOCs-Cold Trap-GC Method-on-Line Monitoring Method (ES 09906.a); The Korea National Institute of Environmental Research: Incheon, Korea, 2018.

7. Perma Pure. Available online: http://www.permapure.com (accessed on 1 August 2019).

8. The Korea National Institute of Environmental Research. Method for the Measurement of Odorants; The Korea National Institute of Environmental Research: Incheon, Korea, 2007.

9. U.S. EPA. Compendium Method TO-17: Determination of Volatile Organic Compounds in Ambient Air Using Active Sampling Onto Sorbent Tubes; U.S. EPA: Cincinnati, OH, USA, 1999.

10. Yang, J.; Conver, T.S.; Koropchak, J.A.; Leighty, D.A. Use of a multi-tube Nafion ${ }^{\circledR}$ membrane dryer for desolvation with thermospray sample introduction to inductively coupled plasma-atomic emission spectrometry. Spectrochim. Acta Part B At. Spectrosc. 1996, 51, 1491-1503. [CrossRef]

11. Jahnke, J.A. Continuous Emission Monitoring, 2nd ed.; John Wiley \& Sons: Hoboken, NJ, USA, 2000.

12. Zielinska, B.; Sagebiel, J.C.; Harshfield, G.; Gertler, A.W.; Pierson, W.R. Volatile organic compounds up to C20 emitted from motor vehicles; measurement methods. Atmos. Environ. 1996, 30, 2269-2286. [CrossRef]

13. McClenny, W.A.; Pleil, J.D.; Evans, G.F.; Oliver, K.D.; Holdren, M.W.; Winberry, W.T. Canister-based method for monitoring toxic vocs in ambient air. J. Air Waste Manag. Assoc. 1991, 41, 1308-1318. [CrossRef]

14. Hsu, J.P.; Miller, G.; Moran, V. Analytical method for determination of trace organics in gas samples collected by Canister. J. Chromatogr. Sci. 1991, 29, 83-88. [CrossRef]

15. Gong, Q.; Demerjian, K.L. Hydrocarbon losses on a regenerated nation ${ }^{\circledR}$ dryer. J. Air Waste Manag. Assoc. 1995, 45, 490-493. [CrossRef]

16. Son, E.-S.; Seo, Y.-K.; Lee, D.-H.; Lee, M.-D.; Han, J.-S.; Baek, S.-O. A Study on the Performanc Optimization of A Continuous Monitoring Method for Hazardous VOCs in the Ambient Atmosphere. J. Korean Soc. Atmos. Environ. 2009, 25, 523-538. [CrossRef]

17. U.S. EPA. Compendium Method TO-14A: Determination Of Volatile Organic Compounds (VOCs). In Ambient Air Using Specially Prepared Canisters With Subsequent Analysis By Gas Chromatography; U.S. EPA: Cincinnati, OH, USA, 1999.

18. Seo, Y.-K.; Chung, S.-H.; Baek, S.-O. Current Status and Prospective of Hazardous VOC in Ambient Air. J. Korean Soc. Atmos. Environ. 2012, 27, 734-745. [CrossRef]

19. Son, Y.S.; Lee, G.; Kim, J.C.; Han, J.S. Development of a pretreatment system for the analysis of atmospheric reduced sulfur compounds. Anal. Chem. 2013, 85, 10134-10141. [CrossRef] [PubMed]

20. Sun, C.Q. Mpemba Paradox: Hydrogen Bond Memory and Water-Skin Supersolidity. arXiv 2015, arXiv:1501.00765.

21. Jeng, M. The Mpemba effect: When can hot water freeze faster than cold? Am. J. Phys. 2006, 74, 514-522. [CrossRef] 
22. The Korea Ministry of Environment. Annual Environmental Report; The Korea Ministry of Environment: Sejong, Korea, 2008.

23. U.S. EPA ISO 16000-6. Indoor Air-Part 6: Determination of Volatile Organic Compounds in Indoor and Test Chamber Air by Active Sampling on Tenax $T A^{\circledR}$ Sorbent, Thermal Desorption and Gas Chromatography Using MS/FID; ISO Copyright Office: Geneva, Switzerland, 2004.

24. U.S. EPA ISO 16017-2. Indoor, Ambient and Workplace Air-Sampling and Analysis of Volatile Organic Compounds by Sorbent Tube/Thermal Desorption/Capillary Gas Chromatography_Part 2: Diffusive Sampling; ISO Copyright Office: Geneva, Switzerland, 2003.

25. U.S. EPA ISO 16017-1. Indoor, Ambient and Workplace Air-Sampling and Analysis of Volatile Organic Compounds by Sorbent Tube/Thermal Desorption/Capillary Gas Chromatography_Part 1: Pumped Sampling; ISO Copyright Office: Geneva, Switzerland, 2000.

26. The Korea Ministry of Environment. Toluene, Xylene, Methyl ethyl Ketone, Methyl Isobutyl Ketone, Butyl Actate, Stylene and i-Butyl Alcohol-Cold Trap/Thermal Desorption-GC Method (ES09307.a); The Korea National Institute of Environmental Research: Incheon, Korea, 2018.

27. The Korea Ministry of Environment. Methods for Determination of Hazardous and Volatile Organic Compounds in Ambient Air-Adsorbent Trap Method (ES 01804.2); The Korea National Institute of Environmental Research: Incheon, Korea, 2016.

28. Deming, B.; Pagonis, D.; Liu, X.; Day, D.; Talukdar, R.; Krechmer, J.; de Gouw, J.A.; Jimenez, J.L.; Ziemann, P.J. Measurements of Delays of Gas-Phase Compounds in a Wide Variety of Tubing Materials due to Gas-Wall Interactions. Atmos. Meas. Tech. Discuss. 2019, 12, 3453-3461. [CrossRef]

29. Dunder, T.A.; Leighty, D.A. Comparison of Thermoelectric and Permeation Dryers for Sulfur Dioxide Removal during Sample Conditioning of Wet Gas Streams; No. CONF-970677-.; Air and Waste Management Association: Pittsburgh, PA, USA, 1997.

30. Kim, D.-J. The Effect of Water Pretreatment Device on Environmental AIR pollutants $\left(\mathrm{O}_{3}, \mathrm{SO}_{2}, \mathrm{CO}\right)$ Measurements and Analysis; Konkuk University: Seoul, Korea, 2018.

31. Im, M.-S.; Ju, D.-W.; Kim, H.-S.; Song, K.-P.; Park, K.-H. A Study of Analytical Method for 4 Legally-designated Compounds [MEK, MIBK, n-Butyl acetate, i-Butyl alcohol] in Ambient Air Using On-line Thermal Desorber with GC/FID. J. Korean Soc. Dor Res. Eng. 2007, 6, 145-153.

(C) 2019 by the authors. Licensee MDPI, Basel, Switzerland. This article is an open access article distributed under the terms and conditions of the Creative Commons Attribution (CC BY) license (http://creativecommons.org/licenses/by/4.0/). 